\title{
Combining Organic and Inorganic Wastes to Form Metal-Organic Frameworks
}

\author{
Eléonore Lagae-Capelle ${ }^{1}$, Marine Cognet ${ }^{1}$, Srinivasan Madhavi ${ }^{2,3}$, Michaël Carboni ${ }^{1, * \mathbb{C}}$ and \\ Daniel Meyer ${ }^{1}$ \\ 1 ICSM, University Montpellier, CEA, CNRS, ENSCM, 30207 Marcoule, France; \\ eleonore.lagae-capelle@cea.fr (E.L.-C.); marine.cognet@cea.fr (M.C.); daniel.meyer@cea.fr (D.M.) \\ 2 School of Materials Science and Engineering, Nanyang Technological University, Singapore 639798, \\ Singapore; madhavi@ntu.edu.sg \\ 3 Energy Research Institute @ NTU, ERI @ N, Nanyang Technological University, Singapore 639798, Singapore \\ * Correspondence: michael.carboni@cea.fr; Tel.: +33-466-339-204
}

Received: 20 December 2019; Accepted: 14 January 2020; Published: 17 January 2020

check for updates

\begin{abstract}
This paper reports a simple method to recycle plastic-bottle and Li-ion-battery waste in one process by forming valuable coordination polymers (metal-organic frameworks, MOFs). Poly(ethylene terephthalate) from plastic bottles was depolymerized to produce an organic ligand source (terephthalate), and Li-ion batteries were dissolved as a source of metals. By mixing both dissolution solutions together, selective precipitation of an Al-based MOF, known as MIL-53 in the literature, was observed. This material can be recovered in large quantities from waste and presents similar properties of purity and porosity to as-synthesis MIL-53. This work illustrates the opportunity to form hybrid porous materials by combining different waste streams, laying the foundations for an achievable integrated circular economy from different waste cycle treatments (for batteries and plastics).
\end{abstract}

Keywords: recycling batteries; recycling plastic bottles; metal-organic frameworks; selective precipitation; hydrometallurgy process

\section{Introduction}

The development of batteries is one of the crucial main directions for the progress of renewable energies, and batteries have been extensively developed as mobile energy sources (e.g., for mobile phones and cars) [1]. Li-ion-battery (LiB) breakthrough technology has had the lion's share of the development since the early 1990s due to the batteries' high energy density and relative safety [2]. LiBs are mainly composed of a cathode, an anode, an electrolyte, and a separator. While the anode is a copper foil coated with a graphite-based material, the cathode is generally an aluminum electroactive-metal-layered material (e.g., based on $\mathrm{Fe}, \mathrm{Ni}, \mathrm{Mn}$, or $\mathrm{Co}$ ). The expected growth in the usage of LiBs along with the induced criticality of some metals (e.g., Co), the regulation of LiBs in several countries, and the toxicity of some battery compounds impose the need to develop efficient recycling processes with low environmental impact [3]. The current recycling processes of batteries are in an early stage of development with limited involvement in a circular economy and are ruled by regulation and the actual economic model. The main issues for future developments are usually the variability in the batteries' composition and the difficulty involved in their collection and recovery from other wastes. Despite the expected criticality of $\mathrm{Co}$, the metal resources needed for the synthesis of batteries are abundant and metal prices are still low (in 2019), posing the challenge for the development of a complex and efficient recycling process [4]. 
In another field, the recycling of plastic waste is also a major societal problem. Only $10 \%$ of all plastics produced are recycled, excluding those that are incinerated [5]. The difficulties in recycling plastic come from the plastics' high variability of composition and their dispersion throughout the countryside. For example, plastic bottles are composed of a non-biodegradable polymer polyethylene terephthalate (PET), which makes up $10 \%$ of plastic production [6]. Downstream products from PET recycling are of low value, making the process (by physical or chemical treatment) not interesting when compared to the low price of virgin PET. Moreover, in addition to making no economic sense, the current recycling of PET has some environmental issues due to the presence of contaminants [7].

Metal-organic frameworks (MOFs) or hybrid porous organic/inorganic materials are a class of crystalline solids organized by the self-assembly of organic linkers with metal ions or clusters [8]. They have strong potential to be used for a wide range of applications due to their specific properties (such as stability, large porosity, or high surface area) [9]. The main issues of these materials remain their synthesis, generally at the gram scale, and the final price of the materials. Recently, these materials have been produced using commercial depolymerized PET as a source of organic ligands to build various MOFs, based on $\mathrm{Zr}$ [10,11], Cu [12], Zn [13], Cr [14,15], Al [14,16], Ga [14], and V [16], with a high purity. We have recently proposed the use of $\mathrm{LiB}$ waste as a source of metal ions for the synthesis of such materials [17-19]. We have developed a LiB recycling approach to obtain $\mathrm{Al} \mathrm{MOFs,} \mathrm{Ni-Mn}$ $\mathrm{MOFs}$, and $\mathrm{Cu} \mathrm{MOF}$ directly from a rough, black mass dissolution solution by successive precipitation using benzene tricarboxylic acid.

By combining the PET and LiNMC (Ni, Mn, Co) waste streams, we have laid the foundation for an integrated recycling process, leading to potential high-value products (such as $\mathrm{Al} \mathrm{MOFs).} \mathrm{The} \mathrm{work}$ was done on real waste-plastic bottles used for regular water and crushed lithium Mn-Ni (LMN) batteries-as depicted in Figure 1.
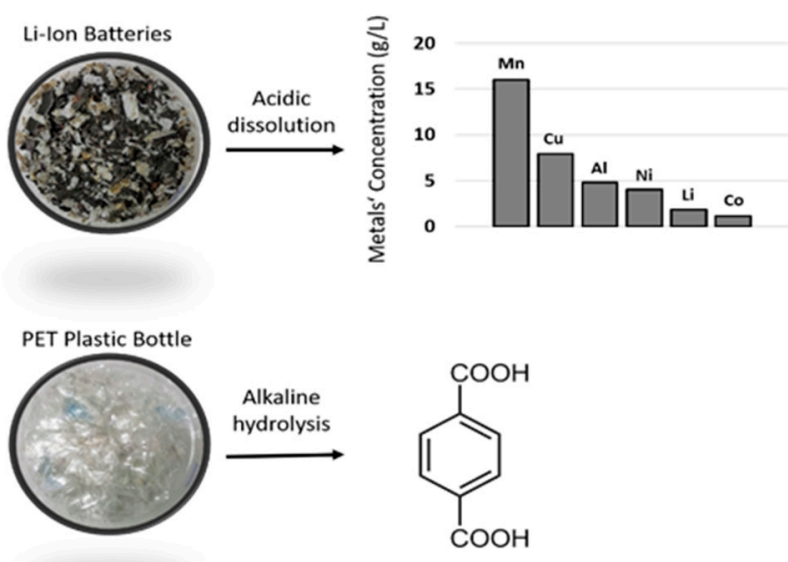

Figure 1. Dissolution of Li-ion batteries (top) and alkaline hydrolysis of plastic bottles (bottom).

\section{Materials and Methods}

\subsection{Materials}

Transparent PET water-bottle waste from various manufacturers (cristaline, evian and volvic, France) was recovered directly from trash cans, and crushed LiB waste, mainly composed of plastics, carbon, and metals, was provided by an industrial manufacturer and used without further physical treatment. Other reagents were purchased from Sigma and were used without any purifications.

A Bruker D8 Advance diffractometer (Bruker, Billerica, MA, USA) equipped with a Cu anode was used for PXRD analysis. SEM images of the materials were recorded with a FEI Quanta 200 environmental scanning electron microscope (ThermoFisher, Waltham, MA, USA) at an acceleration voltage of $30 \mathrm{kV}$ under vacuum. A Mettler-Toledo TG (Mettler-Toledo, Greifensee, Switzerland) with an autosampler was used for TGA. An ASAP 2020 (Micromeritics, Norcross, GA, USA) at $77 \mathrm{~K}$ was used to measure the nitrogen uptake. The samples were outgassing at $200^{\circ} \mathrm{C}$ for $24 \mathrm{~h}$ prior to the analysis, 
and the specific surface areas were determined with the BET method. ${ }^{1} \mathrm{H}$ NMR was recorded at room temperature using a $400 \mathrm{MHz}$ spectrometer (Bruker, Billerica, MA, USA).

\subsection{Protocols}

Depolymerization of PET bottles: $5 \mathrm{~g}$ of plastic bottles (cut into pieces of around $2 \mathrm{~cm}$ ) were introduced to an Erlenmeyer flask with $2.8 \mathrm{~g}$ of solid $\mathrm{NaOH}$ and $50 \mathrm{~mL}$ of ethylene glycol. The solution was slowly stirred and heated to $180^{\circ} \mathrm{C}$ for $12 \mathrm{~h}$. Then, distilled water was added, drop by drop, to solubilize the mixture and to obtain a clear solution (around $50 \mathrm{~mL}$ ).

Dissolution of Li-ion batteries: $15 \mathrm{~g}$ of crushed batteries were added to $150 \mathrm{~mL}$ of $2 \mathrm{~N} \mathrm{HCl}$ solution. The solution was slowly stirred for $24 \mathrm{~h}$. The plastics and carbon materials were removed by filtration and centrifugation and, finally, a clear metal ion solution was obtained. The solution was analyzed by ICP-OES (Figure 1). The concentrations $(\mathrm{g} / \mathrm{L})$ of the elements were $16.0(\mathrm{Mn}), 7.9(\mathrm{Cu}), 4.8(\mathrm{Al}), 4.0(\mathrm{Ni})$, $1.8(\mathrm{Li})$, and $1.1(\mathrm{Co})$. The metal composition was in accordance with LMN-type batteries (i.e., $\mathrm{Al}$ and $\mathrm{Cu}$ were in high concentration and came from the contactors of the battery).

Selective precipitation of MOFs: $530 \mu \mathrm{L}$ of the terephthalate solution (equivalent to $16 \mathrm{mg}$ of ligand) was mixed with $1 \mathrm{~mL}$ of DMF (Dimethylformamide), and $1 \mathrm{~mL}$ of the battery-waste solution and the clear solution was heated to 70 or $90{ }^{\circ} \mathrm{C}$ for $12 \mathrm{~h}$. A precipitate was observed after the solvothermal reaction and was separated by centrifugation. The powder was washed with DMF at 150 ${ }^{\circ} \mathrm{C}$ for one night and washed with $\mathrm{H}_{2} \mathrm{O}$ at $90{ }^{\circ} \mathrm{C}$ for $4 \mathrm{~h}$ before being dried at $90{ }^{\circ} \mathrm{C}$ for $12 \mathrm{~h}$.

\section{Results and Discussion}

Plastic bottles and LiBs can be easily solubilized in alkaline and acidic solutions, respectively. The metal composition of the dissolution solution of batteries was determined by ICP-OES, whereas the ligand concentration in the dissolution solution of PET bottles was determined by ${ }^{1} \mathrm{H}$ NMR. To determine and quantify the terephthalate concentration in this solution, an acidic solution of $\mathrm{HCl}(10$ $\mathrm{mL}$ of a $30 \% \mathrm{HCl}$ solution) was carefully added until the precipitation of a white powder occurred. The powder was centrifuged and washed with water and ethanol and then dried at $90{ }^{\circ} \mathrm{C}$ overnight. The organic product was then isolated, dried, and analyzed by ${ }^{1} \mathrm{H}$ NMR (Figure S1). The peak at $8.04 \mathrm{ppm}$ corresponded to the four aromatic protons of the terephthalate ligand and the peak at $13.27 \mathrm{ppm}$ to the two $\mathrm{COOH}$ functionalities. The peak at $3.40 \mathrm{ppm}$ corresponded to some residual ethylene glycol that came from the hydrolysis of the PET or from the solvent used during the depolymerization reaction. The concentration of ligands in the solution was, in this case, determined as $30 \mathrm{~g} / \mathrm{L}$.

In order to keep the process as simple as possible, quantities of both dissolution solutions were mixed together (carefully) and some DMF was also added to keep the mixture clear, with all components soluble in such conditions. The DMF was crucial to avoid the precipitation of the organic ligand directly after mixing both solutions. After heating at different temperatures $\left(70\right.$ or $\left.90^{\circ} \mathrm{C}\right)$ for $12 \mathrm{~h}$, a white precipitate appeared and was isolated and analyzed.

SEM analysis revealed the formation of well-organized materials with a needle shape of around 10 to $5 \mu \mathrm{m}$ depending on the temperature of the synthesis $\left(90\right.$ and $70{ }^{\circ} \mathrm{C}$, respectively) (Figure $2 \mathrm{a}$ and Figure S2). The materials obtained at $90^{\circ} \mathrm{C}$ appeared more crystalline with thicker and longer needles than those obtained at $70^{\circ} \mathrm{C}$. The EDX measurements of both samples revealed that the materials were composed of $\mathrm{Al}$, showing the selective precipitation of this metal (Tables S1 and S2).

The PXRD patterns of both compounds were very similar and were in accordance with the formation of a crystalline hybrid material (low-angle peaks with broad signals) (Figure $2 b$ ). The patterns corresponded to a previously reported MOF, named MIL-53 (Al) in the literature, based on the same ligands and $\mathrm{Al}$ as the metal node. An extra picture was also observed for the material obtained at $70{ }^{\circ} \mathrm{C}$. This particular material was reported to be flexible, which depended on a stimulus (guest molecules) conducting a reversible change in the material's crystalline structure (high-temperature and low-temperature phases). Here the obtained materials were a mixture of such phases with different guest molecules inside the pore cavities. 


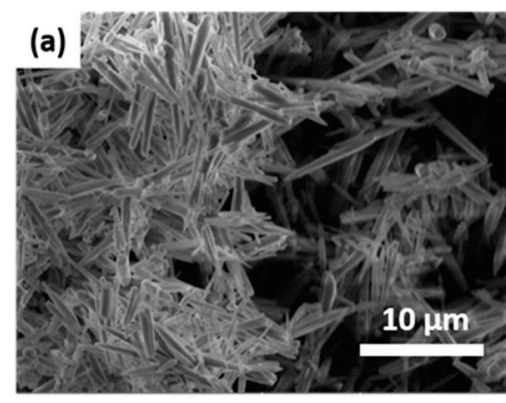

(c)

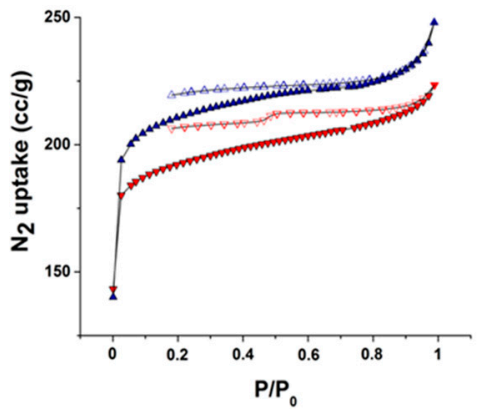

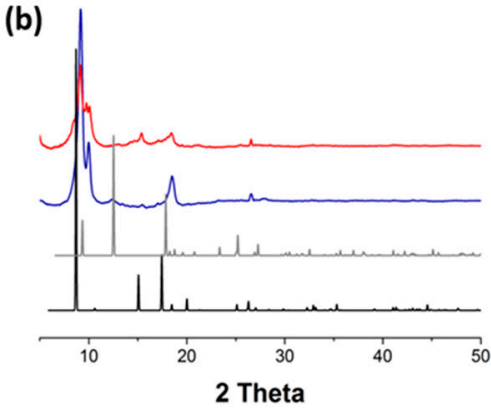

(d)

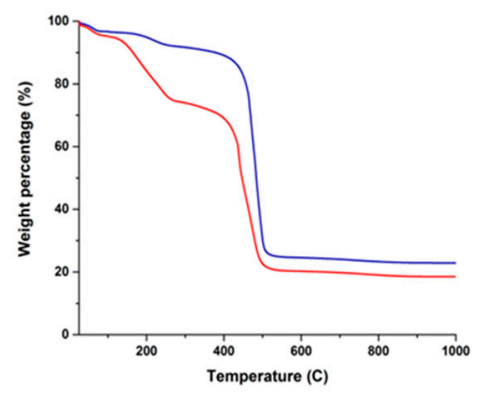

Figure 2. (a) SEM images of the material obtained at $90{ }^{\circ} \mathrm{C}$; (b) PXRD; (c) BET and (d) TGA analyses for the materials obtained at $70{ }^{\circ} \mathrm{C}$ (red) and $90{ }^{\circ} \mathrm{C}$ (blue). The black and gray XRD patterns correspond, respectively, to the simulated $\mathrm{XRD}$ patterns of high-temperature and low-temperature phases of MIL-53 (Al).

Permanent porosity of the MOFs was demonstrated by $\mathrm{N}_{2}$ adsorption at $77 \mathrm{~K}$ and revealed that the materials had a high BET surface area with values of $742 \mathrm{~m}^{2} / \mathrm{g}$ at $70{ }^{\circ} \mathrm{C}$ and $813 \mathrm{~m}^{2} / \mathrm{g}$ at $90{ }^{\circ} \mathrm{C}$ (Figure 2c). These two values are similar to but lower than those reported in the literature (around $1100 \mathrm{~m}^{2} / \mathrm{g}$ ) for as-synthesized materials.

TGA analyses were in accordance with a material with the composition of [AIII $(\mathrm{OH})(\mathrm{BDC})]$ (Figure 2d). A first loss of between 10 and $30 \mathrm{wt.} \%$ (at 90 and $70{ }^{\circ} \mathrm{C}$, respectively) was observed between 100 and $240{ }^{\circ} \mathrm{C}$ and was attributed to some residual solvent molecules (water and/or DMF). This occurred prior to the degradation of the framework at around $450{ }^{\circ} \mathrm{C}$ with the decomposition of the organic ligand to form the corresponding oxide material.

Finally, by mixing the different dissolution solutions corresponding to $5 \mathrm{~g}$ of crushed batteries (containing $240 \mathrm{mg}$ of $\mathrm{Al}$ ) and $3 \mathrm{~g}$ of plastic bottles (containing $1.8 \mathrm{~g}$ of the organic ligand), it was possible to recover around $2.5 \mathrm{~g}$ of $\mathrm{Al} \mathrm{MOF}$ at 70 and $90{ }^{\circ} \mathrm{C}$. By taking into account the formula of the $\mathrm{MOF},\left[\mathrm{Al}{ }^{\mathrm{III}}(\mathrm{OH})(\mathrm{BDC})\right]$, the $\mathrm{Al}$ precipitation was total. After the removal of $\mathrm{Al}$ from the solution, it was not possible to precipitate other metals after adding more plastic-bottle dissolution solution for a second precipitation step in the same conditions.

\section{Conclusions}

For the first time, to our knowledge, a high-quality Al-MOF-type porous material was formed using only two sources of waste-Li-ion batteries and PET plastic bottles. This work mainly focused on the production of one type of MOF. The production of other kinds of $\mathrm{MOF}(\mathrm{Cu}, \mathrm{Ni}, \mathrm{Mn}$, or Co based) may be considered in the near future. The obtained material, known as MIL-53 in the literature, has very similar properties to the material formed with pure chemical compounds. The main issues for the further development of the current approach are the replacement of DMF with a greener solvent and the rationalization of its energy use (i.e., decreasing the temperature). In addition to the low cost of MOF synthesis, the proposed coupling of two kinds of independent waste streams will provide other options for the development of recycling processes. 
Supplementary Materials: The following are available online at http://www.mdpi.com/1996-1944/13/2/441/s1: Figure S1: ${ }^{1} \mathrm{H}$ NMR spectra obtained after the alkaline treatment of the PET plastic, Figure S2: SEM image of the material obtained at $70{ }^{\circ} \mathrm{C}$, Table S1: EDX analysis of the material obtained at $70{ }^{\circ} \mathrm{C}$, Table S2. EDX analysis of the material obtained at $90^{\circ} \mathrm{C}$.

Author Contributions: Synthesis and characterization, E.L.-C. and M.C.; supervision and writing, S.M., M.C., and D.M. All authors have read and agreed to the published version of the manuscript.

Funding: This research was funded by the National Environmental Agency (NEA, Singapore) and the Ministry of National Development (MND, Singapore) with the "Singapore-CEA Alliance for Research in Circular Economy (SCARCE, award number USS-IF-2018-4)", which is a joint laboratory set up between Nanyang Technological University (NTU, Singapore) and the French Alternative Energies and Atomic Energy Commission (CEA, France).

Acknowledgments: The authors are grateful to Fabrice Lorignon and Cyrielle Rey for their help to characterize the materials.

Conflicts of Interest: The authors declare no conflict of interest.

\section{References}

1. Armand, M.; Tarascon, J.-M. Building better batteries. Nature 2008, 451, 652-657. [CrossRef] [PubMed]

2. Susai, F.A.; Sclar, H.; Shilina, Y.; Penki, T.R.; Raman, R.; Maddukuri, S.; Maiti, S.; Halalay, I.C.; Luski, S.; Markovsky, B.; et al. Horizons for Li-Ion Batteries Relevant to Electro-Mobility: High-Specific-Energy Cathodes and Chemically Active Separators. Adv. Mater. 2018, 30, 1801348. [CrossRef] [PubMed]

3. Xu, J.; Thomas, H.; Francis, R.W.; Lum, K.R.; Wang, J.; Liang, B. A review of processes and technologies for the recycling of lithium-ion secondary batteries. J. Power Sources 2008, 177, 512-527. [CrossRef]

4. Tunsu, C.; Petranikova, M.; Gergorić, M.; Ekberg, C.; Retegan, T. Reclaiming rare earth elements from end-of-life products: A review of the perspectives for urban mining using hydrometallurgical unit operations. Hydrometallurgy 2015, 156, 239-258. [CrossRef]

5. Hopewell, J.; Dvorak, R.; Kosior, E. Plastics recycling: Challenges and opportunities. Philos. Trans. R. Soc. B Boil. Sci. 2009, 364, 2115-2126. [CrossRef] [PubMed]

6. Geyer, R.; Jambeck, J.R.; Law, K.L. Production, use, and fate of all plastics ever made. Sci. Adv. 2017, 3, e1700782. [CrossRef] [PubMed]

7. Cheng, X.; Shi, H.; Adams, C.D.; Ma, Y. Assessment of metal contaminations leaching out from recycling plastic bottles upon treatments. Environ. Sci. Pollut. Res. 2010, 17, 1323-1330. [CrossRef] [PubMed]

8. Kirchon, A.; Feng, L.; Drake, H.F.; Joseph, E.A.; Zhou, H.-C. From fundamentals to applications: A toolbox for robust and multifunctional MOF materials. Chem. Soc. Rev. 2018, 47, 8611-8638. [CrossRef] [PubMed]

9. Furukawa, H.; Cordova, K.E.; O'Keeffe, M.; Yaghi, O.M. The Chemistry and Applications of Metal-Organic Frameworks. Science 2013, 341, 1230444. [CrossRef] [PubMed]

10. Zhou, L.; Wang, S.; Chen, Y.; Serre, C. Direct synthesis of robust hcp UiO-66(Zr) MOF using poly(ethylene terephthalate) waste as ligand source. Microporous Mesoporous Mater. 2019, 290, 109674. [CrossRef]

11. Dyosiba, X.; Ren, J.; Musyoka, N.M.; Langmi, H.W.; Mathe, M.K.; Onyango, M.S. Feasibility of Varied Polyethylene Terephthalate Wastes as a Linker Source in Metal-Organic Framework UiO-66 (Zr) Synthesis. Ind. Eng. Chem. Res. 2019, 58, 17010-17016. [CrossRef]

12. Doan, V.D.; Do, T.L.; Ho, T.M.T.; Le, V.T.; Nguyen, H.T. Utilization of waste plastic pet bottles to prepare copper-1,4-benzenedicarboxylate metal-organic framework for methylene blue removal. Sep. Sci. Technol. 2020, 55, 444-455. [CrossRef]

13. Roy, P.K.; Ramanan, A.; Rajagopal, C. Post consumer PET waste as potential feedstock for metal organic frameworks. Mater. Lett. 2013, 106, 390-392. [CrossRef]

14. Lo, S.-H.; Raja, D.S.; Chen, C.-W.; Kang, Y.-H.; Chen, J.-J.; Lin, C.-H. Waste polyethylene terephthalate (PET) materials as sustainable precursors for the synthesis of nanoporous MOFs, MIL-47, MIL-53(Cr, Al, Ga) and MIL-101(Cr). Dalton Trans. 2016, 45, 9565-9573. [CrossRef] [PubMed]

15. Ren, J.; Dyosiba, X.; Musyoka, N.M.; Langmi, H.W.; North, B.C.; Mathe, M.; Onyango, M.S. Green synthesis of chromium-based metal-organic framework (Cr-MOF) from waste polyethylene terephthalate (PET) bottles for hydrogen storage applications. Int. J. Hydrogen Energy 2016, 41, 18141-18146. [CrossRef]

16. Deleu, W.P.R.; Stassen, I.; Jonckheere, D.; Ameloot, R.; De Vos, D.E. Waste PET (bottles) as a resource or substrate for MOF synthesis. J. Mater. Chem. A 2016, 4, 9519-9525. [CrossRef] 
17. Perez, E.; Andre, M.-L.; Amador, R.N.; Hyvrard, F.; Borrini, J.; Carboni, M.; Meyer, D. Recovery of metals from simulant spent lithium-ion battery as organophosphonate coordination polymers in aqueous media. $J$. Hazard. Mater. 2016, 317, 617-621. [CrossRef] [PubMed]

18. Perez, E.; Amador, R.N.; Carboni, M.; Meyer, D. In-situ precipitation of Metal-Organic Frameworks from a simulant battery waste solution. Mater. Lett. 2016, 167, 188-191. [CrossRef]

19. Cognet, M.; Condomines, J.; Cambedouzou, J.; Madhavi, S.; Carboni, M.; Meyer, D. An original recycling method for Li-ion batteries through large scale production of Metal Organic Frameworks. J. Hazard. Mater. 2020, 385, 121603. [CrossRef] [PubMed]

(C) 2020 by the authors. Licensee MDPI, Basel, Switzerland. This article is an open access article distributed under the terms and conditions of the Creative Commons Attribution (CC BY) license (http://creativecommons.org/licenses/by/4.0/). 